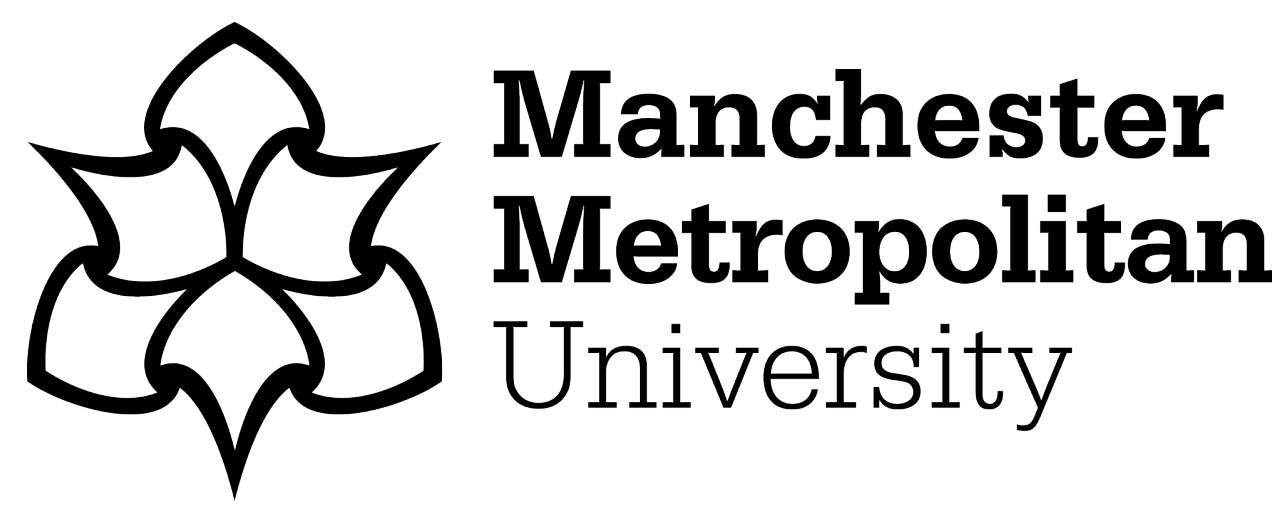

Cranmer, S and Lewin, C (2017) iTEC: conceptualising, realising and recognising pedagogical and technological innovation in European classrooms. Technology, Pedagogy and Education, 36 (3-4). pp. 184-201. ISSN 1475939X

Downloaded from: https://e-space.mmu.ac.uk/618215/

Version: Accepted Version

Publisher: Taylor \& Francis (Routledge)

DOI: https://doi.org/10.1080/1475939X.2017.1299791

Please cite the published version 
To cite this article: Sue Cranmer \& Cathy Lewin (2017) iTEC: Conceptualising, realising and recognising pedagogical and technological innovation in European classrooms. Technology, Pedagogy and Education. Published online. DOI:

$10.1080 / 1475939 X .2017 .1299791$

\title{
iTEC: Conceptualising, realising and recognising pedagogical and technological innovation in European classrooms.
}

\author{
Sue Cranmer ${ }^{\mathrm{a}^{*}}$, Cathy Lewin ${ }^{\mathrm{b}}$ \\ ${ }^{a}$ Department of Educational Research, Lancaster University, Lancaster, UK \\ ${ }^{b}$ Education and Social Research Institute, Manchester Metropolitan University, \\ Manchester, UK
}

*Corresponding author. Email: s.cranmer@lancaster.ac.uk

\section{iTEC: Conceptualising, realising and recognising pedagogical and technological innovation in European classrooms.}

\begin{abstract}
Innovation, a complex concept, underpinned a 4-year pan-European research project designed to increase the effective use of technology in school classrooms. This article revisits evaluation data collected during the project and explores the challenges of conceptualising, realising and researching 'innovation'. We describe how innovation was conceptualised, highlighting key issues, not all of which could be resolved in the project. The development of an approach to support teachers to change their practices facilitated the realisation of innovation in the classroom. This approach, through which researchers and National Pedagogical Co-ordinators worked with teachers to develop their teaching and learning practices with technology in potentially innovative ways, is outlined. Case study data are then used to exemplify how teachers and other stakeholders applied this approach and how they perceived innovation in practice within their
\end{abstract}


own countries. Through a discussion of these cases, the paper highlights the challenge of defining innovation in different country settings and, in turn, the complexity of identifying its occurrence. It concludes by proposing the next steps for similar research endeavours.

Keywords: innovation; digital pedagogy; technology; methodology.

\section{Introduction}

Innovative Technologies for an Engaging Classroom (iTEC) was a 4-year panEuropean research and development project (2010-2014) which focused on the development of educational scenarios to transform pedagogy in schools across Europe. Activities based on the scenarios were piloted and evaluated in over 2500 classrooms. The project involved 26 partners, including 14 Ministries of Education, and was one of the largest initiatives within the European Union to innovate with technology in schools. The rationale for iTEC was recognition by policymakers and stakeholders in European Union Member states that Information and Communication Technologies (ICT) could be a key enabler of innovation in schools for learning (Bocconi, Kampylis and Punie, 2013). At the start of the project, use of ICT in classrooms remained low (EACEA, 2011) and where used did not necessarily lead to a change in pedagogical practices (Law, 2009; Shear, Novais et al, 2010). iTEC, therefore, was conceived to drive innovation by developing and trialling new approaches to teaching and learning, enabled by technology. Given that iTEC involved over 2000 teachers and approximately 50,000 students from across Europe, the resulting datasets can potentially offer new insights to inform research and practice. Here, we have chosen to focus on innovation, and the challenges arising through the project in relation to developing a shared understanding of this underpinning concept, developing structures to support its development, and evaluating the outcomes. 
iTEC's resources were intended to help teachers respond to the day-to-day and systemic challenges they faced by providing them with inspiring pedagogical and technological solutions. The project team sought to develop innovative educational scenarios and created tools such as e-learning environment prototype applications for supporting teaching and learning. Technologies per se were not provided as one aim of the project was to create a sustainable model of scaling up digital pedagogy in schools. Therefore, the expectation was that schools involved would use existing tools and infrastructure. The educational scenarios together with iTEC technologies and other technological tools were piloted in different countries over five overlapping cycles designed to provide opportunities for developing and refining project processes and resources. Piloting took place mainly in lower secondary schools.

A key challenge of the project was to both define what is meant by 'innovation' and to evaluate how it was facilitated by the iTEC process. The evaluation included teacher and student surveys together with case studies, focussed on stakeholders' perceptions. Here, we revisit and reanalyse the qualitative data gathered during iTEC to consider in more depth the challenges relating to conceptualising, realising and researching 'innovation' in classroom practices. We begin by problematizing the concept of innovation and outlining how its definition was understood and developed in the project. This article then sets out the process through which researchers worked with teachers to support the development of their teaching and learning with technology in potentially innovative ways. In turn, it utilises illustrative case study data to exemplify issues of significance, exploring in depth developments in teaching and learning perceived by stakeholders as 'innovative' within their own countries.

In detail, it will ask:

- How can we define and describe innovative digital pedagogies? 
- How do teachers and other stakeholders conceptualise and perceive the development of innovative practices in relation to pedagogy and technology?

- In what ways can innovative practices be judged?

The main focus for this article is drawn from the contribution of two partners in the project: Futurelab and Manchester Metropolitan University. For a full overview of the project and its evaluation, please see Ellis, Blamire and Van Assche (2015); Lewin and McNicol (2015). Stakeholders engaged in the project were teachers, universities, policy makers, technology companies, and not-for-profit organisations promoting education.

\section{Innovation through ICT in education}

\section{The challenges of conceptualising, recognising and sustaining 'innovation'}

Educational innovation supported by ICT frequently underpins government initiatives and policies which seek to prepare students for a competitive 'knowledgebased' global economy in order to drive economic interests (Moyle, 2010). Thus, it is a commonly used concept. Yet, innovation is difficult to define given that concepts such as 'new' and 'better' rely on the subjective assessment of the value of an innovation (Moyle, 2010). Rogers suggests that innovation is 'an idea, practice, or object that is perceived as new by an individual' $(2003$, p.12) which provides benefits through impact on learning and/or improved efficiency (Miles, 1964; Kirkland and Sutch, 2009). The OECD/CERI (2010) definition asserts that within education and training, innovation is '... any dynamic change intended to add value to the educational process and resulting in measurable outcomes, be that in terms of stakeholder satisfaction or educational performance' (p.14). The Institute for Prospective Technological Studies (IPTS) has noted that whilst innovation has no generally accepted single definition, it is typically considered to be: an intentional and deliberate activity; designed to be of benefit to 
individuals, teams or organisations; about change and novelty; a 'dynamic and unpredictable social process'; and 'occurs in a specific political, sociocultural, economic, technological, and organisational context that influences its development, diffusion, and use' (Kampylis, Bocconi and Punie, 2012, p.6). Innovation is necessarily context-dependent and therefore no single tool or practice will be seen as 'innovative' in every classroom (OECD, 2013). The degree of innovation has also been defined in various ways. 'Incremental' innovation (also described as 'sustaining') is defined as progressive change, building on and improving existing practices (Christiansen et al., 2008; Leadbeater and Wong, 2010; Kampylis et al., 2012). At the opposite extreme, 'disruptive' (also described as 'radical') innovation completely redefines practices or creates new opportunities (Christensen et al., 2008; Leadbeater and Wong, 2010) leading to 'a profound and comprehensive change' (Kampylis et al., 2012, p.9). Judging what counts as innovative is also a difficult and challenging task. Rogers (2003) claims that innovation is a matter of 'perception' not an absolute. A practice perceived as innovative by a teacher just beginning to integrate technology into pedagogy may not be perceived as innovative by a teacher with lots of experience of technology in the classroom. As Somekh (2007, p.8) notes 'the difficulty in understanding the process of innovation is that we see it necessarily from our own standpoint'. Zhao and Frank (2003) conclude that educational change is multifaceted and relational so that determining the success of an educational innovation relies on the different dimensions of influence and activity within a wider ecological framework. Moreover, Fullan (2007) maintains that educational change and innovation must take into account local contexts, relationships, power configurations and the subjective realities of those involved. Valuable work has already been undertaken in relation to identifying and assessing innovative classroom practices (Law, 2014). For example, in 
the SITES M2, project case studies of innovative practices were analysed using a scoring rubric, the Dimension of Innovation, to measure absolute levels of innovativeness (Law et al, 2005).

Sustaining and scaling up effective innovative projects in education is also challenging (Brečko et al, 2014; Bocconi et al, 2013; Kozma, 2003) and requires the identification of mechanisms for supporting system-wide change (Brečko et al, 2014). Rogers suggests that incremental, individual, small-scale changes can support and lead to a broader set of local innovations in his 'diffusion' model of innovation (2003). Moreover, the OECD state that small-scale interventions 'are usually the most permanent and make the deepest impact on practice' (OECD, 2008, p.17). Conversely, it has been argued that 'more disruptive innovations are more difficult to scale up' (Kampylis et al, 2013, p.131-2). Thus, incremental innovation is most likely to be successful and indeed is the most common approach in educational contexts (Kampylis et al., 2013) as it is in the workplace (Toner, 2011). It is claimed that there is no single approach to scaling up innovation but instead there is a need for scaling up strategies to support 'multiple pathways and ecological diversity in innovation' (Kampylis et al, 2013, p.133). Furthermore, the ability to scale up depends on the development of flexible innovations that are effective irrespective of context and particular circumstances (Dede, 2011).

\section{Conceptualising innovation within iTEC}

Research was taken account of which showed the necessity of balancing the development of innovative pedagogies with innovative technologies through taking a pedagogical lead in innovation design. For this purpose, a distinction was made in iTEC between technological and pedagogical innovation. ICTs do not in and of themselves 
generate sustained change and innovation in teaching and learning (Somekh, 2007; Zemsky and Massy, 2004). Pedagogical innovation, rather than technological innovation, was at the core of iTEC, and viewed as critical to effective adoption of technology-enabled learning (Ertmer and Ottenbreit-Leftwich, 2013; Kampylis et al., 2013; Mor and Mogilevsky, 2013). That is, the project focused on 'how, not what, technology should be used to achieve meaningful learning outcomes' (Ertmer and Ottenbreit-Leftwich, 2013, p.175, emphasis as in original).With this in mind, a design process was developed to create innovative educational scenarios which could support teachers to change their pedagogical practices. That is, taking a teacher's starting point, whatever that might be; the aim was to support innovation in the classroom through the development of digital pedagogy.

Conceptualising 'innovation' as an underpinning concept in iTEC proved to be more challenging than anticipated. A working definition of innovation within iTEC was originally considered to be essential both to facilitate a shared understanding of the project aims and also to ensure a range of innovation across the scenarios and other project outputs. For this purpose, a working group was set up and proposed a definition: 'Innovation in iTEC consists of potentially scalable learning activities that provide beneficial pedagogical and technological responses to educational challenges and opportunities' (Cranmer, Perrotta, Oldfield, and Payton, 2013, p.36). The complexity of the concept of innovation combined with the multifarious character of iTEC made it almost impossible to operationalise this definition at every stage of the project. Moreover, given the large numbers, diverse backgrounds and different contexts of people involved in the project, it was challenging to reach complete agreement across all project partners. It was important to move forward with the project regardless of this lack of consensus. To do this, working definitions of innovation were revisited and 
revised at particular significant points during the project so that work could continue. For example, in the later stages of the project, it became necessary to also distinguish between absolute innovation, which was defined as 'innovative in any context' and relative innovation which was defined as 'more innovative than [a teacher's] current practice' (Ulicsak, 2014).

\section{Realisation of innovation: The iTEC approach for supporting the development of innovative digital pedagogies}

\section{Educational scenario development and monitoring}

iTEC was designed to drive forward innovation through the development of educational scenarios enabled by technology. The project was designed to address current realities in contrast to other more 'blue sky' scenario development initiatives (e.g. Ducatel, 2010). There were five overlapping cycles of scenario development, monitoring and reflection, feeding into ongoing process refinement.

iTEC scenarios were defined as narrative descriptions of teaching and learning that provided a vision for innovation and advanced pedagogical practices enabled by ICT. (See the iTEC scenario library http://itec.eun.org/web/guest/scenario-library.) For this purpose, scenarios were built upon current trends and drivers that affect and are affected by education such as external economic, social or technological factors which were recognised as important and/or could influence the context. They were noncurriculum specific to allow for localisation and widest applicability. Initially, scenarios were developed by groups of experts and key stakeholders. Subsequently, the process was adapted to include teachers, head teachers and students, and also to enable the process to be managed at national and local levels rather than facilitated by the project team. This was considered to be important as teacher ownership and engagement are 
considered essential for innovation (Coburn, 2003; Kirkland and Sutch, 2009; Law, 2014). For a detailed account of the scenario development process, see Cranmer and Ulicsak (2015).

\section{Scenarios into schools: piloting and evaluating learning stories and activities}

A scenario selection process was developed to identify which scenarios to develop further. The final version of this process included six dimensions, one of which was 'Innovation' which included criteria such as novelty, pedagogical benefits, technology integration and student-centred approaches. Those scenarios selected were developed further by Aalto University, Finland, drawing on principles of research-based design (Leinonen et al., 2008; Leinonen et al., 2010). The process, described in more detail by Toikannen, Keune and Leinonen (2015), again involved teachers and stakeholders in team work and participatory design. It identified challenges and opportunities relating to the implementation of scenarios; identified suitable resources (tools, services, content, people and events) to address challenges and support implementation; and documented the resulting package of 'Learning Activities', which were concrete descriptions of discrete actions. Each cycle, a small number of 'Learning Stories', narrative overviews of learning developed from the original scenarios which exemplified the package of Learning Activities, were provided.

In each of the first four cycles, National Pedagogical Co-ordinators (NPCs) chose how many Learning Stories to make available to participating teachers, depending on the local context. Some teachers were thus offered a choice whilst others were asked to pilot a specific Learning Story. The Learning Story was not a prescriptive lesson plan but a resource to inspire the teacher to experiment with new approaches and a wider range of technologies. Teachers commonly adapted the ideas and selected parts 
of the Learning Story to meet their individual needs, harnessing available technologies to facilitate the learning. In this sense, each implementation was unique.

\section{Recognising degrees of innovation: the Dimensions of Innovation rubric}

To negotiate the complexity of defining and measuring innovation, we have chosen to use the Dimensions of Innovation (Law et al., 2005) which identifies six dimensions of innovation: intended curriculum goals of the innovative practices; pedagogical role(s) of the teachers; role(s) of the students; nature and sophistication of the ICT used; multidimensional learning outcomes exhibited; and connectedness of the classroom. For each of these dimensions, the rubric provides descriptors for traditional, emergent and highly innovative practices, thus providing a means of comparing levels of innovation. (See rubric at http://sitesdatabase.cite.hku.hk/i_classroom/P 3 1.htm). The degrees of change for each dimension are identified as: traditional, some new elements, emergent, innovative and most innovative. For example, teachers' pedagogical role ranges from presenting and explaining (traditional), to providing authentic learning contexts (most innovative). Despite the fact that this instrument was developed over 10 years ago, we consider that the descriptors are still relevant today and provide a useful and rigorous way of systematically interrogating the iTEC evaluation results. It can readily be used to judge evidence of absolute innovation as well as identify the degree of change for an individual teacher. This framework was specifically chosen due to its good fit with the aims, objectives and dimensions of innovation identified within iTEC.

\section{Methods}

This section provides an overview of the methods, sampling and analytical approaches adopted in the evaluation of the iTEC project. The case studies selected to illustrate the 
realisation of innovation in the iTEC project were conducted in the fourth cycle of piloting and so specific details of this data collection round are also presented.

The evaluation of iTEC included case studies and teacher surveys, conducted during each of the five cycles of piloting. In each country, a national pedagogical coordinator (NPC, appointed by the Ministry of Education or its nominated agency) undertook the case study data collection and arranged for the translation of the survey instruments into the national language. To ensure consistency and rigour, a handbook of data collection procedures and interview schedules was developed, revised for each cycle evaluation. NPCs also attended a briefing workshop at the beginning of each cycle.

Case studies involved conducting interviews with the teacher, the ICT coordinator (if applicable), the head teacher and a group of 6-8 students together with a lesson observation. These multiple perspectives provide a form of triangulation through bringing together the different accounts. In cycles 1-3, each NPC provided two case study reports, for which they were given a template, and one set of raw data (transcribed and translated). In cycles 4-5, each NPC provided one set of raw data only.

The teacher survey was administered online to all participating teachers in all five cycles. In the first three cycles, the main body of questions concerned the impact of the implementation on teachers' classroom practices. In addition, they were asked about the potential of the Learning Story for innovation and wide scale uptake. In the final two cycles, the focus of questions changed to pedagogical and technological differences and the potential of iTEC technologies, as well as impact on student learning outcomes.

National pedagogical coordinators adopted different approaches to selecting teachers to participate in each cycle. In some cases, teachers were selected through a process which drew on existing networks of innovative practitioners and/or personal 
recommendations; in other cases, there were open calls for participation. In cycle 4, there were 874 pilots (a teacher could run one or two pilots), and 342 individual teachers responded to the teacher survey.

The case studies of implementations of the iTEC process were purposively selected by the NPCs according to specified criteria, detailed in the evaluation handbook for each cycle (for example, from schools that were representative of those participating in iTEC, from schools with adequate technology provision, from a range of subject areas). The case studies were, therefore, not intended to be representative of the country in which they were conducted. NPCs were requested to ensure that teachers selected for case studies in cycle 4 used applications developed within iTEC and/or radically innovative scenarios and/or nationally developed scenarios. In cycle 4, 13 case studies were undertaken. Despite NPCs being given meticulous guidance and support for data collection, the raw data were of varying quality resulting in some case studies providing richer insights than others. For this paper, two case studies were purposively selected firstly to provide sufficiently detailed data to enable analysis of the Dimensions of Innovation to be undertaken and secondly to reflect contrasting experiences of innovation. Only five of the 13 case studies conducted in cycle 4 were sufficiently detailed. Data from the survey responses of the teachers involved were used to select two case studies reflecting contrasting experiences. Specifically teachers were asked to rate their level of competence using ICT to support teaching and learning, together with the perceived changes in their pedagogical approach to use of technology as a result of participating in the project. The two cases thus represent a teacher who perceived that implementing the Learning Story did not lead to much pedagogical and technological change, and a teacher who felt that it led to substantial pedagogical and technological change. 
Case study summaries were constructed through thematic analysis of data from interviews and lesson observations, describing the project undertaken, innovations, problems, solutions and the resources used. For this paper, the raw data from interviews and observations were subsequently re-analysed using a thematic approach, drawing on the Dimensions of Innovation framework. Each case presented below also includes an analysis of the country context derived from a review of relevant literature and a description of the local context derived from case study data. In addition, each case concludes with reflections on changes in practices that were perceived to have taken place. Quantitative data were analysed descriptively using SPSS.

In cycle 4 (March 2013 - June 2013), the Learning Stories and Learning Activities presented for large-scale piloting focused on authentic learning through 'real world' challenges. The three learning stories presented to teachers in cycle 4 were:

- Tell a Story - Narrating an academic topic through audiovisual means.

- Create an Object - Developing a tangible design.

- Create a Game - Constructing a playful activity.

The two case studies presented below exemplify 'Tell a Story' and 'Create an Object'.

\section{Norway: The innovator/early adopter}

\section{Country context}

ICT in education has been promoted through Norwegian policy for over three decades (Søby, 2013). Norway is considered to be one of the few countries with 'digitally supportive schools' (EC, 2013): schools with well-developed ICT policies, incentives for ICT use, and good support structures such as professional development and technical support. Moreover, infrastructure is amongst the best in Europe (EC, 2013), one of the key factors that 'are crucial in reaching effective integration of ICT in education' (Biagi and Loi, 2013), inevitably leading to particularly high access (Erstad, 
2014). However, there is still variation in pedagogical use and digital competence (EC, 2013; Hatlevik et al, 2015).

\section{Local context}

This case concerns an experienced male teacher who was already a highly innovative practitioner (as perceived by himself, the head teacher and the ICT coordinator), teaching in a country that was arguably more advanced in the adoption of ICT to support learning and teaching than many other European countries. The head teacher was supportive and felt that innovation was necessary. However, it was noted that a lack of digital skills and teacher interest in technology amongst staff at the school remained a challenge. The iTEC approach was seen by both the head teacher and the ICT co-ordinator to fit well with the school vision and ICT strategy.

\section{Curriculum goals}

The teacher chose the Learning Story 'Create an Object' as the inspiration for his project which was designed to combine learning outcomes for mathematics, IT and RLE (religion, life philosophy and ethics). His students were aged 14-15, worked in groups of 2-5, and were described by the teacher as being motivated and selfdisciplined. The teacher initially gave a presentation about sacred buildings and the major religions. Then:

[the students working autonomously in groups] had to choose a [religious] building, and find its measurements. They were to make a Padlet [a multimodal shared document or 'wall'] where they would document all the work, the work process and the product. They were to make a plan for the work and talk to other students ... and get their responses. They were to create the building in Sketchup or Minecraft, and present it to the rest of the class. (Teacher interview)

Students identified building measurements through searching the Internet, emailing or 
telephoning local experts (e.g. a member of the local church). Finally, the building designs were printed in $3 \mathrm{D}$, facilitated by the local university. Here, the curriculum goals incorporate the most innovative aspects of Law and colleagues' (2005) rubric as students engaged in a collaborative project inspired by the maker movement (McKay and Peppler, 2013; Peppler and Bender, 2013), followed a design process and reflected on their experiences throughout. The use of technology to recreate a sacred building in 3D gave the task an authentic edge, emulating the design processes commonly used in architecture and building design.

\section{Teacher and student roles}

In terms of pedagogy, the teacher did not perceive that his approach had changed very much at all; he said that he always used a range of different teaching methods and strategies. He was familiar with cross-curricular approaches and experienced in all three subject areas. The teacher noted that keeping students on task was particularly challenging, especially for those groups using Minecraft. He felt that the most novel aspect of the project was asking students to publish and present their designs to an audience:

It's useful for those [students] who do it properly, who do it well, those who make the presentation and get a proper response. It's important in this phase of the work, and this is what stands out most [compared to] the way I usually work on such projects. (Teacher interview)

The teacher's pedagogical role could be considered to have more innovative aspects (Law et al., 2005) through supporting an enquiry approach, team building and collaboration. He also mediated access between students and 'experts' such as local church members, as well as dealing directly with the local university who provided access to the $3 \mathrm{D}$ printer. 
Students were expected to reflect on their own learning at regular intervals. The students felt that their experience had been very different from 'sitting and writing'. They appreciated the hands-on experience, the development of their digital skills, increased autonomy and opportunities for collaboration with peers. Again, through the lens of the Dimensions of Innovation rubric (Law et al., 2005), the students' role had aspects of most innovative elements such as peer evaluation, reflection, engaging in enquiry and collaboration, as well as necessarily experiencing traditional activities such as listening and following instructions.

\section{ICT used}

For this project, the students used a variety of ICT tools. They used a collaborative tool for recording and sharing reflections, Sketchup or Minecraft to create a virtual model of a sacred building and finally, 3D printing (facilitated by the local university) to produce a real model, arguably innovative uses of technology. The teacher encouraged the students to learn how to use the required tools through accessing tutorials on YouTube, thus supporting student independence. 3D printing was perceived by the teacher to be a 'bit of a gimic'. Nevertheless, this opportunity enabled the teacher to develop a better understanding of this technology and how easily it can be integrated into a project.

Students felt that the benefits of technology were that it was easier to find out information, thus making the process of learning more efficient, and that technology makes learning more enjoyable. The teacher felt that the use of technology provided new opportunities for cross-curricular learning:

I suddenly discovered the interdisciplinary potential: you can do something with

Sketchup in RLE. You can combine mathematics and RLE by using computer 
technology. That's the way it often happens - good ideas just turn up out of the blue.

\section{Connectedness}

Interestingly, the connectedness of classrooms and students (i.e. collaborating with different classes within school, community groups outside school or students from different countries) was limited, reflecting the way in which the project was structured. Some (but not all) student groups gathered measurement data for their chosen (local) sacred building by contacting members of the community. And one group of students who had created a model of a local church presented their 3D design to the vicar. In relation to connectedness (Law et al., 2005), this case study evidences a more traditional approach in that the main collaboration occurred only between students within one class.

\section{Learning outcomes}

The teacher said that it was challenging to measure the learning outcomes. However, he believed that his students developed a better understanding of sacred buildings, developed new digital skills, made use of mathematical concepts and experienced the product design cycle 'from an idea to a finished product'. Students agreed that they had developed new digital skills. The teacher noted that students' skills in digital literacy, creativity and problem solving had improved, and to a lesser extent so had their skills in collaboration, critical thinking, communication and independent learning. Students noted in particular that their digital literacy had improved. The teacher also felt that his students' levels of interest and engagement had improved; again students who were interviewed echoed this. In one notable case a student who was normally very difficult to engage, had been particularly motivated by the project. Another student who was very quiet in the classroom had been able to really express 
himself, according to the teacher. The learning outcomes could be considered to be innovative (Law et al., 2005) given that students kept a reflective log, were involved in peer evaluation and generated authentic products (building models) as part of their learning activities.

\section{Changes in practices}

This case study teacher believed that innovation meant 'using things in new ways, or using new things' to achieve improved learning outcomes. In relation to this project, he noted that he used technologies which he had not developed expertise in but was already familiar with. However, he did not feel that this took him out of his comfort zone; he felt his level of competency in using ICT in teaching and learning was already very high (rated $8,1=$ none, 10=very high).

This teacher perceived that there had been very little change in his pedagogical approach (rated 2, 1=not different, 10=radically different) and use of technology (rated 3, $1=$ not different, $10=$ radically different). However, he said that he had developed a better understanding of 3D printing and how it could support teaching and learning. He also observed an increased use of technology in the classroom and noted that asking students to present their work to an audience was particularly novel. Moreover, students in particular remarked on how different their lessons were and that they appreciated the increased use of ICT, development of digital skills, increased autonomy and peer collaboration. Therefore, they perceived that incremental innovation did occur.

In sum, from the teacher's own perspective the iTEC project had not impacted on his own practice (as an already very innovative and competent user of technology) yet students perceived that their experiences were markedly different. 


\section{Portugal: a case of perceived radical innovation}

\section{Country context}

In Portugal, a national strategy was implemented from 2007 to develop infrastructure, as well as teachers' and students' digital skills (Lewin et al., 2011). By the end of the project, positive changes had been made. Schools had been given greater autonomy through decentralisation and there was an expectation that students and teachers would use ICT for learning and teaching. Infrastructure in Portugal had become well-developed with over $80 \%$ of all students across primary and secondary levels having access to a VLE (EC, 2013). In secondary schools more than $45 \%$ of students were being taught by 'digitally confident and supportive' teachers (EC, 2013). Whilst Portuguese teachers' use of ICT in the classroom had become higher than average in relation to other European countries, their students' use was about average (EC, 2013).

\section{Local context}

This case concerns an experienced female teacher of mathematics who perceived that she already had a reasonably high level of competency in using ICT to support learning and teaching (rated 7, $1=$ none, $10=$ very high) and had been involved in previous cycles of iTEC and similar initiatives to iTEC. Her students already used technology to support teaching and learning, for example, Geogebra, but not on a regular basis. The head teacher was supportive of innovation through ICT.

\section{Curriculum goals}

The teacher chose the Learning Story 'Tell a Story'. The teacher asked students to create a video presentation about the areas and volumes of solids, using either MovieMaker or PowToon (a tool for creating animated videos and presentations). 22 students were involved aged 13 to 17 years old, organised into groups. In relation to the 
Dimensions of Innovation (Law et al., 2005), curriculum goals had advanced degrees of innovation including inquiry, communication, collaborative and organisational skills.

\section{Teacher and student roles}

The teacher felt that her role as a facilitator had increased slightly as the students became more autonomous than they had been previously. However, she noted that her teaching approach had always been student-centred.

In relation to the student role, the teacher said that students:

... not only they use [technology] but they also produce [digital resources], maybe that's the biggest difference. .... Here, the learning objective also focuses on production, and in that sense it's even more active, it demands more effort from [students].

Students enjoyed collaborating with and supporting their peers although of course some faced challenges in doing this, particularly in relation to coordinating tasks. It was notably different from their 'regular classes' and enabled students to 'get a break from routine'. One student commented:

In this class we work in groups, in the regular classes we work individually; in this class we work with new technologies and in the other class we usually write on our notebooks and use the book; in these classes we learn how to work in groups, get to know each other, the teacher is more attentive; and in the other classes, the teacher is attentive, of course, but in general not individually.

Students' roles were innovative (Law et al., 2005) primarily involving peer collaboration, engaging in enquiry, and managing and reflecting on their learning.

\section{ICT used}

The project involved MovieMaker and PowToon to edit video footage and produce video presentations. Students also recorded reflections on their progress through blogs 
and a tool created in iTEC called TeamUp. Some students had used MovieMaker at home and were therefore familiar with the tool (preferring its use to PowToon, an unfamiliar tool). Students noted issues in relation to managing large files and school computers being slow. At home they used alternative video-editing tools such as Camtasia. Students were thus making use of ICT at emergent and innovative levels (Law et al., 2005) (rather than the most innovative level) because they were building on use of multimedia production tools and collaboration tools they had previously used only at home.

\section{Connectedness}

There was no innovation in relation to connectedness (Law et al., 2005) as students operated in a traditional way, with no collaboration with others beyond the classroom. However, student interviews revealed that some learners were supported informally at home by family members in relation to resolving technical issues.

\section{Learning outcomes}

In terms of learning outcomes, the teacher noted that the project was particularly engaging for low ability students leading to a slight improvement in their results. Students of average and high ability performed according to expectations. The teacher felt that, in particular, students developed their digital literacy skills. She also noted that their collaborative skills, creativity skills, problem solving skills and ability to engage in independent learning improved. In addition, she believed that the students' interest and engagement had improved, which was corroborated by students' accounts of their experiences. In relation to degree of innovation, the production of a group presentation/multimedia product can be considered as emergent (Law et al., 2005). In 
addition, students had also kept a log of learning through TeamUp and blogs which was judged to be innovative.

\section{Changes in practices}

As in the previous case, we now consider the extent of change as perceived by the Portuguese teacher. This teacher primarily associated innovation with the use of new technologies that 'normally are not used in class'. The teacher felt that innovation through the Learning Story came from creating videos, group work, student autonomy in relation to collating and presenting video content, and the depth of explanations in the videos. She noted that '[the Learning Story] made me leave my comfort zone and well beyond.' However, this related specifically to the creation of videos which the teacher said she would repeat in the future to create her own resources but would not replicate with her students. For her, the challenges faced (e.g. installing MovieMaker on the school laptops, compatibility issues with the video editing software) were greater than the potential benefits. 'As for the video, as I've already said, I'm not really keen to do it unless there was a different technology available'. She noted that she would, however, ask students to create more interactive presentations using Prezi and PowToon. Webbased tools which are simple to use were perceived to be easier to integrate.

As a result, she felt that there had been a substantial change in her pedagogical approach (rated 8, $1=$ not different, $10=$ radically different). Also, despite feeling that she already had a reasonably high level of ICT competence she felt that her classroom use of technology changed (rated 8,1=not different, 10=radically different). Students also noted how different their experiences had been in relation to their regular classes. Students said that they enjoyed collaborating with their peers and were more engaged and 'relaxed' as a result and that this made learning easier. Therefore, in relation to the 
teacher's starting point, we argue that radical innovation occurred although her iTEC led practices may not seem particularly innovative in contrast to others.

In sum, whilst this teacher was already a confident user of technology, she perceived that she had made radical changes both in her pedagogy and use of technology and this change was also perceived by her students.

\section{Conceptualisation, Realisation and Recognition in Practice}

We now discuss the important process and methodological challenges for the iTEC project concerning the conceptualisation, realisation and recognition of innovative digital pedagogies. Use of the Dimensions of Innovation rubric (Law et al., 2005) enabled us to systematically interrogate the data more closely and make judgements about the absolute level of innovation (i.e. innovative in any context) that took place. In addition, we draw on data relating to perceived change in practices to consider the relative level (i.e. change from teacher's previous practice) of innovation that took place.

Conceptualisation of innovation in iTEC was particularly challenging. As outlined earlier, innovation is an inherently difficult term to define due to its complexity and multidimensionality (Moyle, 2010; Kampylis et al., 2012). There remained a tension throughout the project between 'incremental' and 'disruptive' innovation, particularly that which involved state of the art technologies which could be described in terms of 'absolute innovation' (i.e. innovative in any context). 'Disruptive' innovation was an expectation of some parties involved in the project which was funded through the European Commission Framework 7 ICT programme in response to a call for 'Learning in the $21^{\text {st }}$ Century: large-scale pilots for the design of the future classroom'. However, the many educationalists involved in the project, including the national coordinators appointed by the participating Ministries of Education, were in 
strong agreement that 'incremental innovation' was most likely to result in permanent change, in accordance with claims made by others (OECD, 2008; Kampylis et al., 2013).

Distinguishing between pedagogical and technological innovation was a challenge both for teachers and for the researchers, particularly early in the project as we negotiated a shared meaning. Moreover, pedagogical innovation can be achieved through the integration of 'ordinary technology' (Kozma, 2003). The project team and other interested parties engaged in intense debate around what would count as innovation and whether it was considered to be beneficial or worthy of documenting and reporting. Arguably, using existing technology in new ways is indeed innovative and could potentially be radical depending on how the pedagogical approach changes.

Innovation remained understood in different ways by different stakeholders as exemplified across the national case studies; it is inherently subjective. In the Norwegian context, a highly digitally competent teacher considered that there had been very little change in either pedagogical approach or uses of technology; whilst a similarly highly digitally competent teacher in Portugal considered there had been a substantial change in her pedagogical approach and use of technology. The Dimensions of Innovation rubric (Law et al., 2005) enabled us to critically examine the teacher accounts. For example, in looking closely at the students' roles in the Norwegian activities, the rubric enabled us to draw out more innovative elements such as peer evaluation, reflection, engaging in enquiry and collaboration. It also highlighted that whilst the Portuguese teacher felt that she had radically changed her practice, in absolute terms her implementation may not be judged as highly innovative.

In relation to supporting the realisation of innovation in European classrooms, the process itself and, in particular, how the scenario selection process worked in 
practice constrained the innovation potential. Scenarios perceived to be radically innovative were rejected for further development due to concerns about feasibility. National coordinators acted as gatekeepers in some cases by restricting the number of Learning Stories offered to teachers, again on the grounds of feasibility. Finally, as the underlying philosophy of the scenarios was to provide sources of inspiration and not prescriptive lesson plans, teachers could be selective and adapt the resources to suit their own needs. This continual filtering process meant that what teachers actually implemented was often conservative in our view in relation to the original ideas proposed at the start of the process.

Consideration of the data through the lens of the rubric revealed differences between the teachers' views, the students' views and that of the researchers. These differences of perception exemplify a key problematic in the identification of innovative practices through self-reporting measures. In this example, context and roles are significant. Moreover, teacher perceptions are grounded in their experience and knowledge. So for example, research suggests that 3D printing can shorten the 'make' phase in design projects, support the development of coding skills and develop 3D visualization skills (Department for Education (DfE), 2013). Whilst, it cannot be assumed that this UK research will necessarily transfer to the Norwegian setting, it contrasts with the teacher's view here that 3D printing may be a 'bit of a gimic'. Another issue with the data is that the Norwegian teacher's responses to the qualitative measures and quantitative assessment of changes in his own practice are not consistent.

In turn, the recognition of potentially innovative practices is challenging due to the complex issues surrounding their definition and the dependence on context. Nevertheless, analysing the case studies according to the different elements of the rubric does show innovation only took place in some dimensions (Law et al., 2005). For 
example, in both country contexts, teachers reported benefits in terms of engaging wider groups of learners within the area of learning outcomes. In Norway, a quiet learner had expressed themselves more; in Portugal, lower ability learners slightly improved their grades. However, 'connectedness' (collaboration beyond the classroom) remained limited in both settings. This suggests that whilst an absolute measure of innovation within a project like this may not be feasible or appropriate, using the rubric does enable a more fine-tuned analysis of where change has occurred.

A further complexity added to this, is that Law et al.'s Dimensions of Innovation (2005) by itself does not take account of a teacher's starting point and extent of change, thus making it difficult to judge incremental and disruptive levels of innovation. This limitation did not support the key evaluation interest in the project of pedagogical and technological change. In relation to using the rubric, we also noted that whilst most of the elements remain current and relevant, the exception is the ICT dimension which unsurprisingly does not reflect the current range of technologies available.

We conclude our discussion with some recommendations for future research in this field. Firstly, reaching consensus about how innovation is defined is critical. This could be improved by building the process of defining innovation into similar projects from the outset. Everyone should be involved from students and teachers, to project team members, the project officer and external reviewers. The process should be systematic. If it is undertaken extensively at the outset of a project it can inform all subsequent activities from scenario selection, to teacher adaptation of resources and the evaluation of their use.

Secondly, in the iTEC project the ideas that were implemented in the classroom were much more conservative than the original scenarios. Greater involvement of teachers directly in the scenario development process and more support provided for 
teachers in future projects could encourage them to take greater risks in the classroom.

Direct involvement of teachers is important given that in the current process the national coordinator assesses the feasibility of the scenario from the outset, with the consequence that the innovative potential could be diminished. Work could be undertaken with school leaders to develop a culture of change in participating schools. Moreover, continued conversations with participating teachers about what counts as innovative would be helpful.

Thirdly, measurement of innovation could be improved. The Dimensions of Innovation (Law et al, 2005) could be developed further, particularly the ICT dimension which would benefit from updating to reflect technological developments over the last decade. As context is crucial in making judgements about innovation it would be beneficial to develop national, regional and/or local versions of the matrix. In order to better map the extent of change for an individual teacher it may be possible to add a quantitative indicator to each element of the matrix (aligned to categories of incremental/disruptive) to show the degree of change. Alternatively, the matrix could be used as a reflection tool when conducting interviews with teachers to ask them to comment on their previous and current practice. Of course the ideal situation would be to get individual teachers to self-report about their activities in detail prior to participating in a pilot and again on completion of the pilot. This may not be feasible in large-scale pilots due to the additional time and data analysis required.

\section{Conclusion}

This paper has explored some of the methodological issues faced in the iTEC project in relation to the conceptualisation, realisation and recognition of innovation in European classrooms. Through revisiting the valuable data sets gathered through the project evaluation and the application of the Dimensions of Innovation rubric, the 
challenges of conceptualising and researching innovation have been explored. The lynch pin to resolving many of these issues is developing a shared understanding of what is meant by innovation. The iTEC project was large-scale, international and complex in its design, all of which meant that developing a shared understanding of innovation was even more difficult than it might have otherwise been. As well as issues relating to conceptualisation, we have also highlighted the challenges relating to realising and recognising innovation in digital pedagogies. Although we have reflected on possible ways to address these challenges in our discussion above, we suggest that further research in this area is necessary in order to better understand how to support innovation in the classroom. iTEC provided a unique and timely opportunity to highlight methodological issues relating to facilitating and evaluating pedagogical innovation. This paper contributes to current debates concerning innovation and technology enhanced learning, and can usefully inform future research in this field.

\section{Acknowledgements}

We would like to thank the teachers and other stakeholders who participated in iTEC and on whom the success of the project was dependent. Also, European Schoolnet as coordinators; and our colleagues, particularly Alison Oldfield, who prepared a literature review on Innovation for the iTEC project which has influenced our thinking, Mary Ulicsak who undertook much of the later development work on this aspect of the project and Sarah McNicol who collated the case study data.

\section{Funding}

This work was supported by the European Commission (Grant agreement $\mathrm{N}^{\mathrm{o}} 257566$ ) 


\section{Notes on contributors}

Dr Sue Cranmer is lecturer in technology enhanced learning, Department of Educational Research, Lancaster University. Her research interests are mainly focussed on uses of digital technologies for learning, social justice and in/equality. Previous projects have included research into digital innovation, digital pedagogy, inclusive pedagogical design and digital literacy. Before joining Lancaster University, Sue worked as a Senior Researcher at Futurelab.

Cathy Lewin is professor of education in the Education and Social Research Institute, Manchester Metropolitan University. Her research interests concern the use of technology to support educational change in schooling and young people's use of technology in formal, nonformal and informal settings. She has more than 20 years' experience of evaluating technology use in schools for both the UK government and the European Commission.

\section{References}

Biagi, B., \& Loi, M. (2013). Measuring ICT use and learning outcomes: evidence from recent econometric studies. European Journal of Education, 48, $28-42$.

Bocconi, S., Kampylis, P., \& Punie, Y. (2013). Framing ICT-enabled innovation for learning: the case of one-to-one learning initiatives in Europe. European Journal of Education, 48(1), 113-130.

Brečko, B.N., Kampylis, P., \& Punie, Y. (2014). Mainstreaming ICT-enabled innovation in education and training in Europe: Policy actions for sustainability, scalability and impact at system level. JRC Scientific and Policy Reports, JRC-IPTS, Seville, Spain.

Coburn, C. (2003). Rethinking scale: Moving beyond numbers to deep and lasting change. Educational Researcher, 32(6), 3-12.

Christensen, M.C., Horn, M.B., \& Johnson, C.W (2008). Disrupting class: How disruptive innovation will change the way the world learns. New York: McGraw Hill Publishers. 
Cranmer, S., \& Ulicsak, M. (2015). Development of the future classroom toolkit. In F. Van Assche, Anido, L., Griffiths, D., Lewin, C., \& McNicol, S. (Eds.), Reengineering the uptake of ICT in schools: The iTEC project. (17-39). Springer Verlag: Amsterdam.

Cranmer, S., Perrotta, C., Oldfield, A., \& Payton, S. (2013) D2.2 Summary report of scenario development process. Brussels, Belgium: European Schoolnet. Retrieved from http://itec.eun.org/web/guest/deliverables

Dede, C. (2011). Reconceptualizing technology integration to meet the necessity of transformation. Journal of Curriculum and Instruction, 5(1), 4-16.

Department for Education (DfE). (2013). 3D printers in schools: Uses in the curriculum. Retrieved from https://www.gov.uk/government/uploads/.../3D_printers_in_schools.pdf. Ducatel, K. (2010). Scenarios for ambient intelligence 2010. A report by the IST Advisory Group (ISTAG) to the EU. DG INFSO, Seville, Spain: IPTS. Retrieved from ftp://ftp.cordis.europa.eu/pub/ist/docs/istagscenarios2010.pdf Education, Audiovisual and Culture Executive Agency (EACEA) (2011). Key data on learning and innovation through ICT at school in Europe 2011. Brussels: EACEA. Retrieved from http://bookshop.europa.eu/en/key-data-on-learningand-innovation-through-ict-at-school-in-europe-2011-pbEC3011094/.

Ellis, W., Blamire, R., \& Van Assche, F. (2015). Innovative technologies for an engaging classroom (iTEC). In F. Van Assche, Anido, L., Griffiths, D., Lewin, C., \& McNicol, S. (Eds.), Re-engineering the uptake of ICT in schools: The iTEC project. (1-15). Springer Verlag: Amsterdam.

Erstad, O. (2014). The expanded classroom - spatial relations in classroom practices using ICT. Nordic Journal of Digital Literacy, 9(1), 8- 22.

Ertmer, P.A., \& Ottenbreit-Leftwich, A. (2013). Removing obstacles to the pedagogical changes required by Jonassen's vision of authentic technology-enabled learning. Computers \& Education, 64, 175-182.

European Commission (2013). Survey of schools: ICT in education, final study report: Benchmarking access, use and attitudes to technology in Europe's schools. Brussels: European Commission. Retrieved from https://ec.europa.eu/digitalagenda/node $/ 51275$

Fullan, M. (2007). The new meaning of educational change (Fourth Edition). New York: Teachers College Press. 
Hatlevik, O.E., Ottestad, G., \& Throndsen, I. (2015). Predictors of digital competence in 7th grade: a multilevel analysis. Journal of Computer Assisted Learning, 31, $220-231$.

Kampylis, P., Bocconi, S., \& Punie, Y. (2012). Towards a mapping framework of ICTenabled innovation for Learning. JRC-IPTS Working Papers JRC72277. Seville: Spain: Institute for Prospective and Technological Studies, Joint Research Centre.

Kampylis, P., Law, N., Punie, Y., Bocconi, S., Brečko, B., Han, S., Looi, C.-K., \& Miyake, N. (2013). ICT-enabled innovation for learning in Europe and Asia: Exploring conditions for sustainability, scalability and impact at system level. Luxembourg: Publications Office of the European Union.

Kirkland, K., \& Sutch, D. (2009). Overcoming the barriers to educational innovation. A literature review. Bristol: Futurelab. Retrieved from http://www.nfer.ac.uk/publications/FUTL61/FUTL61_home.cfm

Kozma, R.B. (Ed) (2003). Technology, innovation and educational change: a global perspective. Eugene, Or: International Association for Technology in Education.

Law N. (2009). Mathematics and science teachers' pedagogical orientations and their use of ICT in teaching. Education and Information Technologies, 14(4), 309323.

Law N., Chow, Y., \& Yuen, H.K. (2005). Methodological Approaches to Comparing Pedagogical Innovations Using Technology. Education and Information Technologies, 38(1-2), 7-20.

Law, N. (2014). Comparing pedagogical innovations. In Bray, M., Adamson, B. \& Mason, M. (Eds.) Comparative education research: Approaches and methods. 2nd Edition. Hong Kong: CERC and Springer.

Leadbeater, C., \& Wong, A. (2010). Learning from the extremes. San Jose, CA, Singapore and Amsterdam: Cisco Systems, Inc.. Retrieved from http://www.cisco.com/web/about/citizenship/socioeconomic/docs/LearningfromExtremes_WhitePaper.pdf

Leinonen, T., Purma, J., Põldoja, H., \& Toikkanen, T. (2010). Information architecture and design solutions scaffolding authoring of open educational resources. IEEE Transactions on Learning Technologies, 99(1). 
Leinonen, T., Toikkanen, T., \& Silfvast, K. (2008). Software as hypothesis: Researchbased design methodology. Paper presented at the Participatory Design Conference, Indiana University, Bloomington, USA.

Lewin, C; \& McNicol, S. (2015). The impact and potential of iTEC: Evidence from large-scale validation in school classrooms. In F. Van Assche, Anido, L., Griffiths, D., Lewin, C., \& McNicol, S. (Eds.), Re-engineering the uptake of ICT in schools: The iTEC project. (163-186). Springer Verlag: Amsterdam.

Lewin, C., Savage, J., Haldane, M., Whitton, N., \& Blamire, R. (2011). The knowledge map: Innovative classroom practice with digital technologies. Manchester, UK: Manchester Metropolitan University. Retrieved from http://itec.eun.org/c/document_library/get_file?p_ 1 id=10307\&folderId=37321 \&name=DLFE-1631.pdf

McKay, C., \& Peppler, K. (2013). MakerCart: A mobile fab lab for the classroom. Position Paper presented at the Interaction Design for Children Conference (IDC), New York, NY.

Miles, M. (Ed) (1964). Innovation in education. New York, NY: Columbia University, Teachers College Bureau of Publications.

Mor, Y., \& Mogilevsky, O. (2013). The learning design studio: collaborative design inquiry as teachers' professional development. Research in Learning Technology, 21: 22054. Retrieved from http://dx.doi.org/10.3402/rlt.v21i0.22054.

Moyle, K. (2010). Building innovation: Learning with technologies (Australian Education Review No. 56). Melbourne: ACER.

OECD (2008). Innovating to learn, learning to innovate. Paris: OECD Publishing.

OECD/CERI (2010) Inspired by technology, driven by pedagogy: a systemic approach to technology-based school innovations, educational research and innovation. Paris: OECD Publishing.

OECD (2013). Innovative learning environments. Paris: OECD Publishing. Retrieved from http://dx.doi.org/10.1787/9789264203488-en

Peppler, K., \& Bender, S. (2013). Maker Movement spreads innovation one project at a time. Phi Delta Kappan, 95(3), 22-27.

Rogers, E.M. (2003). Diffusion of innovations. $5^{\text {th }}$ Edition. New York: Free Press.

Shear, L., Novais, G., Moorthy, S., \& Langworthy, M. (2010). Innovative teaching and learning research: Executive summary of pilot year findings. Redmond, US: 
Microsoft Partners in Learning. Retrieved from

http://itlresearch.com/images/stories/reports/ITL\%20Research\%20Pilot\%20Year \%20Executive\%20Summary\%20Oct\%202010\%20F.pdf

Søby, M. (2013). Synergies for better learning - where are we now? Nordic Journal of Digital Literacy, 8(1-2), 3-12.

Somekh, B. (2007). Pedagogy and learning with ICT: Researching the art of innovation. London: Routledge.

Toikannen, T., Keune, A., \& Leinonen, T. (2015). Designing Edukata, a participatory design model for creating learning activities. In F. Van Assche, Anido, L., Griffiths, D., Lewin, C., \& McNicol, S. (Eds.), Re-engineering the uptake of ICT in schools: The iTEC project. (41-58). Springer Verlag: Amsterdam.

Toner, P. (2011). Workforce skills and innovation: An overview of major themes in the Literature. OECD Education Working Papers, No. 55. Paris: OECD Publishing. Retrieved from http://dx.doi.org/10.1787/5kgk6hpnhxzq-en

Ulicsak, M. (2014). D2.4 Final report on the pedagogical scenario building process. Brussels, Belgium: European Schoolnet. Retrieved from http://itec.eun.org/web/guest/deliverables

Zemsky, R., \& Massy, W.F. (2004). Thwarted innovation: What happened to e-learning and why. Philadelphia, PA: The Learning Alliance, University of Pennsylvania http://immagic.com/eLibrary/ARCHIVES/GENERAL/UPENN_US/P040600Z.p df

Zhao, Y., \& Frank, K.A. (2003). Factors affecting technology uses in schools: an ecological perspective. American Educational Research Journal, 40, 807-840. 